\title{
Emerging journals
}

\author{
The benefits of and challenges for publishing scientific journals in and by emerging countries
}

\section{Rogerio Meneghini}

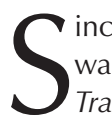

the first scientific journal founded-The Philosophical 1665-the number of journals dedicated to publishing academic research has literally exploded. The Thomson Reuters Web of Knowledge database alone-which represents far less than the total number of academic journals_-includes more than 11,000 journals from non-profit, society and commercial publishers, published in numerous languages and with content ranging from the natural sciences to the social sciences and humanities. Notwithstanding the sheer scale and diversity of academic publishing, however, there is a difference between the publishing enterprise in developed countries and emerging countries in terms of the commercial rationale behind the journals.

\section{...'national' or even 'local' journals are published and supported because they report important, practical information that would be declined by international journals...}

Although all academic journals seek to serve their readership by publishing the highest quality and most interesting advances, a growing trend in the twentieth century has also seen publishers in developed countries viewing academic publishing as a way of generating profit, and the desire of journal editors to publish the best and most interesting science thereby serves the commercial interest of publishers who want people to buy the publication.

In emerging countries, however, there are few commercial reasons to publish a journal. Instead, 'national' or even 'local' journals are published and supported because they report important, practical information that would be declined by international journals, either because the topic is of only local or marginal interest, or because the research does not meet the high standards for publication at an international level. Consequently, most 'national' journals are not able to finance themselves and depend on public funding. In Brazil, for instance, the national journals account for one-third of the publications of all scientific articles from Brazil and are mostly funded by the government. Other emerging countries that invest in research-notably China, India and Russia-also have a sizable number of national journals, most of which are published in their native language.

There is little competition between developed countries to publish the most or the best scientific journals. There is clear competition between the top-flight journalsNature and Science, for example-but this competition is academically and/or commercially, rather than nationally, based. In fact, countries with similar scientific calibres in terms of the research they generate, differ greatly in terms of the number of journals published within their borders. According to the Thomson Reuters database, for example, the Netherlands, Switzerland and Sweden published 847, 202 and 30 scientific journal, respectively, in 2010 - the Netherlands has been a traditional haven for publishers. However, the number of articles published by researchers in these countries in journals

To overcome the perceived dominance of international journals [...] some emerging countries have increased the number of national journals indexed by Thomson Reuters-a rough measurement of scientific productivity — does not differ significantly.

$\mathrm{S}$ cientists who edit directly or serve on the editorial boards of high-quality, international journals have a major responsibility because they guide the direction and set the standards of scientific research. In deciding what to publish, they define the quality of research, promote emerging research areas and set the criteria by which research is judged to be new and exciting; they are the gatekeepers of science. The distribution of these scientists also reflects the division between developed and emerging countries in scientific publishing. Using the Netherlands, Switzerland and Sweden as examples, they respectively contributed 235, 256 and 160 scientists to the editorial teams or boards of 220 highimpact, selected journals in 2005 (Braun \& Diospatonyi, 2005). These numbers are comparable with the scientific production of these countries in terms of publications. On the other hand, Brazil, South Korea and Russia, countries as scientifically productive in terms of total number of articles as the Netherlands, Switzerland and Sweden, contributed only 28, 29 and 55 'gatekeepers', respectively. A principal reason for this difference is, of course, the more variable quality of the science produced in emerging countries, but it is nevertheless clear that their scientists are under-represented on the teams that define the course and standards of scientific research.

To overcome the perceived dominance of international journals, and to address the significant barriers to getting published that their scientists face, some emerging countries have increased the number of national journals (Sumathipala et al, 2004). Such 
barriers have been well documented and include poor written English and the generally lower or more variable quality of the science produced in emerging countries. However, although English, which is the lingua franca of modern science (Meneghini \& Packer, 2007), is not as great a barrier as some would claim, there is some evidence of a conscious or subconscious bias among reviewers and editors in judging articles from emerging countries. (Meneghini et al, 2008; Sumathipala et al, 2004).

\section{...to not publish, for any reason, is to break the process of science and potentially inhibit progress}

A third pressure has also forced some emerging countries to introduce more national journals in which to publish academic research from within their borders: greater scientific output. During the past two or three decades, several of these countries have made huge investments into research-notably China, India and Brazil, among others-which has enormously increased their scientific productivity. Initially, the new national journals aspired to adopt the rigid rules of peer review and the quality standards of international journals, but this approach did not produce satisfactory results in terms of the quality of papers published. On the one hand, it is hard for national journals to secure the expertise of scientists competent to review their submissions; on the other, the reviewers who do agree tend to be more lenient, ostensibly believing that peer review as rigorous as that of international journals would run counter to the purpose of making scientific results publicly available, at least on the national level.

$\mathrm{T}$ he establishment of national journals has, in effect, created two parallel communication streams for scientists in emerging countries: publication in international journals - the selective routeand publication in national journals - the regional route. On the basis of their perceived chances to be accepted by an international journal, authors can choose the route that gives them the best opportunity to make their results public. Economic conditions are also important as the resources to produce national journals come from government, so national journals can face budget cuts in times of austerity. In the worst case, this can

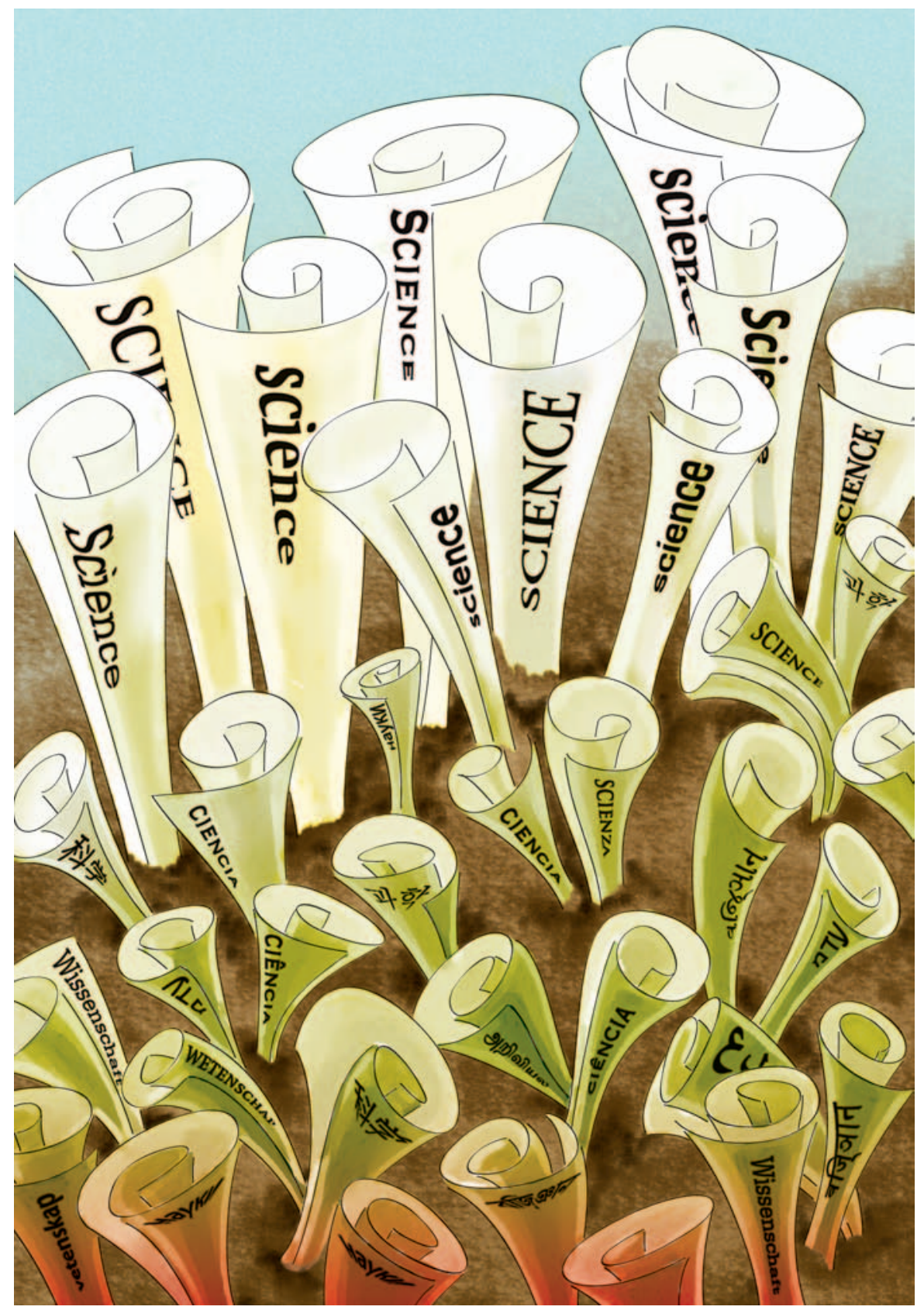

lead to the demise of national journals to the disadvantage of authors who have built their careers by publishing in them.

There is some anecdotal evidence that authors who often or almost exclusively publish in international journals hold national journals in some contempt-they regard them as a way of avoiding the effort and hassle of publishing internationally. Moreover, although the way in which governments regard and support the divergent routes varies between countries, in general, scientists who endure and succeed through the selective route often receive more prestige and have more influence in shaping national science policies. Conversely, authors who choose the regional publication route regard their efforts as an important contribution to the dissemination of information generated by the national scientific community, which might otherwise remain locked away-by either language or access policies. Either way, it is worth mentioning that publication is obviously not the end point of a scientific discovery: the results should feed into the pool of knowledge and might inspire other researchers to pursue new avenues or devise new experiments. 
Hence, to not publish, for any reason, is to break the process of science and potentially inhibit progress.

The choice of pursuing publication in regional or international journals also has direct consequences for the research being published. The selective, international route ensures greater visibility, especially if the paper is published in a high-impact journal. The regional route also makes the results and experiments public, but it fails to attract international visibility, in particular if the research is not published in English.

1 seems that, for the foreseeable future, this scenario will not change. If it is to change, however, then the revolution must be driven by the national journals. In fact, a change that raises the quality and value of national journals would be prudent because it would give scientists from emerging countries the opportunity to sit on the editorial boards of, or referee for, the resulting high-quality national journals. In this way, the importance of national journals would be enhanced and scientists from emerging countries would invest effort and gain experience in serving as editors or referees.

The regional route has various weaknesses, however, the most important of which is the peer-review process. Peerreview at national journals is simply of a lower standard owing to several factors that include a lack of training in objective research assessment, greater leniency and tolerance of poor-quality science, and an unwillingness by top researchers to participate because they prefer to give their time to the selective journals. This creates an awkward situation: on the one hand, the inability to properly assess submissions, and on the other hand, a lack of motivation to do so.

Notwithstanding these difficulties, most editors and authors of national journals hope that their publications will ultimately be recognized as visible, reliable sources of information, and not only as instruments to communicate national research to the public. In other words, their aspiration is not only to publish good science-albeit of lesser interest to international journals-but also to attain the second or third quartiles of impact factors in their areas. These journals should eventually be good enough to compete with the international ones, mitigating their national character and attracting authors from other countries.
T he key is to raise the assessment procedures at national journals to international standards, and to professionalize their operations. Both goals are interdependent. The vast majority of national journals are published by societies and research organizations and their editorial structures are often limited to local researchers. As a result, they are shoestring operations that lack proper administrative support and international input, and can come across as amateurish. The SciELO (Scientific Electronic Library Online), which indexes national journals and measures their quality, can require certain changes when it indexes a journal, including the requirement to internationalize the editorial body or board.

\section{...experienced international editors should be brought in to strengthen national journals, raise their quality and educate local editors...}

In terms of improving this status quo, a range of other changes could be introduced. First, more decision-making authority should be given to publishers to decide how to structure the editorial body. The choice of ad hoc assistants - that is, professional scientists who can lend expertise at the editorial level should be selected by the editors-who should also assess journal performance. Moreover, publishers should try to attract international scientists with editorial experience to join a core group of two or three chief or senior editors. Their English skills, their experience in their research field and their influence in the community would catalyse a rapid improvement of the journals and their quality. In other words, experienced international editors should be brought in to strengthen national journals, raise their quality and educate local editors with the longterm objective to join the international scientific editing community. It would eventually merge the national and the selective routes of publishing into a single international route of scientific communication.

Of course, there is a long way to go. The problem is that many societies and organizations do not have sufficient resources-money or experience-to attract international scientists as editors. However, new publishing and financial models could provide incentives to attract this kind of expertise. Ultimately, relying on government money alone is neither a reliable nor sufficient source of income to make national journals successful. One way of enhancing revenue streams might be to switch to an open-access model that would charge author fees that could be reinvested to improve the journals. In Brazil, for instance, almost all journals have adopted the open access model (Hedlund et al, 2004). The author fees-around US\$1,250 — if adopted, would provide financial support for increasing the quality and performance of the journals. Moreover, increased competition between journals at a national level should create a more dynamic and competitive situation among journals, raising the general quality of the science they publish. This would also feed back to the scientific community and help to raise the general standards of science in emerging countries.

\section{CONFLICT OF INTEREST}

The author declares that he has no conflict of interest.

\section{REFERENCES}

Braun T, Diospatonyi I (2005) The counting of core journal gatekeepers as science indicators really counts. The scientific scope of action and strength of nations. Scientometrics 62: 297-319

Hedlund T, Gustafsson T, Björk BC (2004) The open access scientific journal: an empirical study. Learned Publishing 7: 199-209

Meneghini R, Packer AL (2007) Is there science beyond English? Initiatives to increase the quality and visibility of non-English publications might help to break down language barriers in scientific communication. EMBO Rep 8: 112-116

Meneghini R, Packer AL, Nassi-Calò L (2008) Articles by Latin American authors in prestigious journals have fewer citations. PLOS ONE 3: e3804

Sumathipala A, Siribaddana S, Patel V (2004) Underrepresentation of developing countries in the research literature: ethical issues arising from a survey of five leading medical journals. BMC Med Ethics 5: 1-6

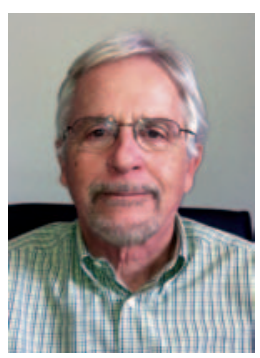

Rogerio Meneghini is the Scientific Coordinator of the Scientific Electronic Library SciELO in São Paulo, Brasil.

E-mail: rogerio.meneghini@scielo.org

EMBO reports (2012) 13, 106-108; published online 13 January 2012; doi:10.1038/embor.2011.252 